\title{
DOSSIÊ - EDUCAÇÃO DE JOVENS, ADULTOS E IDOSOS (EJA) E EDUCAÇÃO PARA AS RELAÇÕES ÉTNICO-RACIAIS E MOVIMENTOS SOCIAIS
}

Ementa: Na fronteira, a interculturalidade é a base das relações do estar com o outro, de estar em outro país, de estar em contato com o diferente. Então, no âmbito dos estudos humanísticos multidisciplinares, este grupo de trabalho propõe a discussão da interculturalidade na Educação de Jovens, Adultos e Idosos (EJA) e na Educação para as Relações Étnico-raciais e Movimentos Sociais. Com base em resultados de pesquisas dos/as coordenadores/as, o GT buscará refletir sobre o papel pedagógico da comunidade escolar fronteiriça na promoção da cidadania de indígenas, quilombolas, afrodescendentes, jovens, adultos, idosos e latino-americanos na diversidade. O GT fundamenta-se no ponto de vista da sociabilidade, quando múltiplas cidadanias revelam que o reconhecimento do "outro" é a melhor maneira de extinguir preconceitos e discriminações, principalmente após a promulgação das leis brasileiras 10.639/03 e 11.645/08, que incluem as culturas e histórias afro-indígenas no ensino nacional. Destaca-se que a escola e os espaços de educação são ambientes potencialmente capazes de reduzir as disparidades entre os seres humanos. Por fim visa-se também, por meio desse grupo de trabalho, fomentar a interdisciplinaridade e propiciar a troca de saberes com diferentes pesquisadores/as.

\section{Coordenadores:}

Dra. Simone Silva Alves (Universidade Federal do Pampa - Campus Jaguarão); Dra. Sátira Pereira Machado (Universidade Federal do Pampa - Campus Jaguarão); Me. Everton Fêrrêr de Oliveira (Universidade Federal do Pampa - Campus Jaguarão) e Ma. Juliana Silva dos Santos (Universidade Federal do Pampa- Campus Jaguarão) 